\title{
Book Review Buchbesprechung Livre nouveau
}

Glenn C. Conroy: Primate Postcranial Remains from the Oligocene of Egypt. Contributions to Primatology, vol.8. Karger, Basel 1976. VI + 134 pp., 28 fig., 36 tab.; SFr./ DM 63,-/US \$ 24.25. Although I supervised the writing of Dr. Conroy's PhD dissertation, I feel no ethical uncertainties about reviewing this edited and partly rewritten version. Dr. Conroy's monograph will take its place among the 'classics' of paleontology; it is an extremely thorough, scholarly, and well-documented description and analysis of some of the most important primate fossils recovered in the last 50 years. Conroy has been most fortunate in having access to the primate postcranial remains recovered during the 1960's by Yale University expeditions led by Prof. Elwyn Simons to the Oligocene deposits of the Fayum Province in Egypt. They constitute the only sample of catarrhine postcranial specimens known prior to the Neogene, and as such are of major importance for understanding the origins and early evolution of the infraorder.

Following a literate introduction and history of study, Conroy discusses the taphonomy and fossil associations of quarry I in the Jebel el Qatrani Formation, 1 of the 2 most important Yale primate quarries. This is followed by detailed morphological and statistical analyses of Fayum humeri, ulnae, radii, tali, and calcanei. On the basis of faunal associations, morphology, and morphometrics, these postcranials are considered to be primate and not those of any other mammalian order (rodents or carnivores). In the main they are assigned to Apidium, although one ulna is considered to be Aegyptopithecus.

The morphological descriptions and comparative anatomical analyses of each bone are carefully and thoroughly detailed. Comprehensive discussions of the likely functional meaning of anatomical features are followed in each case by morphometric analyses. Measurements selected for their presumed functional significance have been taken on the Fayum specimens and on a series of platyrrhines, prosimians, and Cercopithecus and combined in a number of principal components and discriminant function analyses. These produce results which are, for the most part, readily interpretable. Presumed Apidium specimens resemble most closely the New World arboreal quadrupeds Cebus and Saimiri; probably Apidium species resembled these platyrrhines in their positional behavioral repertoires. The single supposed Aegyptopithecus ulna is rather similar to that of the New World howler monkey, Alouatta, a rather slugghish arboreal quadruped capable of some suspensory positional behaviors.

As far as they are known postcranially, the Oligocene catarrhines resemble the living platyrrhines much more closely than they do the extant cercopithecoids (now seen to be a late flowering group with many rather derived traits and thus a poor choice for an early catarrhine 'model'). This also seems to be the case for the early Miocene east African hominoids whose postcranial skeletons show an interesting mix of 'platyrrhine', 'hominoid', and 'primitive' (but few 'cercopithecoid') features.

There is still a great deal of progress to be made in understanding the evolution and diversification of the Anthropoidea. Dr. Conroy's monograph is a good example of the solid yet imaginative work necessary for such an understanding.

David Pilbeam, New Haven Conn. 